\title{
FORMAÇÃO E AÇÃO: REFLEXÕES SOBRE A EDUCAÇÃO AMBIENTAL NO CURSO DE GRADUAÇÃO EM GEOGRAFIA DA UNIVERSIDADE DE COIMBRA - PORTUGAL
}

Rogério Gerolineto Fonseca ${ }^{1}$

Maria Beatriz Junqueira Bernardes ${ }^{2}$

Resumo: A degradação das condições ambientais e a diminuição da disponibilidade de certos recursos naturais contribuíram, nas últimas décadas, para o aumento das discussões sobre a importância de mudanças de atitude da sociedade. Este artigo tem como objetivo apresentar a percepção dos alunos portugueses de cursos de graduação em Geografia da Universidade de Coimbra (Portugal) sobre a educação ambiental. O instrumento utilizado para a pesquisa foi um questionário, aplicado a um grupo de cinquenta alunos. Os resultados evidenciam a importância da universidade e das mídias na tomada de consciência e na determinação dos hábitos por parte dos alunos, além da possibilidade de se aprofundar ainda mais as abordagens sobre educação ambiental nos cursos de graduação em geografia.

Palavras-chave: Tomada de Consciência Ambiental; Ensino Superior; Graduandos; Geografia.

${ }^{1}$ Mestrando em Geografia pela Universidade Estadual Paulista "Julio de Mesquita Filho" Campus de Rio Claro - UNESP-RC. E-mail: rogeriogfonseca@yahoo.com.br.

2 Professora Doutora do curso de Geografia da Universidade Federal de Uberlândia - UFU. Email: mariabeatrizjunqueira@gmail.com.

Revbea, São Paulo, V. 10, № 4: 40-57, 2015. 


\section{Introdução}

A Educação Ambiental tem recebido cada vez mais importância na sociedade, pois perpassa por todas as áreas do conhecimento. Assim, o seu caráter interdisciplinar possibilita contribuir para o estudo de várias áreas, como a biologia, a ecologia, a agronomia e a geografia, entre outras. Isto ocorre devido ao fato de a humanidade (essa mesma humanidade que degrada) ter percebido um aumento da ocorrência das catástrofes ambientais provocadas pelo homem e a diminuição dos recursos naturais pelo seu uso indiscriminado. Desta forma, visando minimizar os eventos catastróficos e garantir a disponibilidade dos recursos, tem-se discutido cada vez mais sobre as formas de uso e ocupação do espaço geográfico e a inserção da sociedade no meio ambiente, de modo a formar pessoas mais comprometidas com a promoção de uma melhor qualidade ambiental.

Este trabalho é fruto de uma experiência de mobilidade internacional de um estudante de geografia da Universidade Federal de Uberlândia, campus Pontal, que cursou um ano letivo de estudos na Universidade de Coimbra, Portugal, entre setembro de 2010 e julho de 2011. Esta enriquecedora experiência possibilitou não apenas o contato com culturas e sistema de ensino diferentes, mas, também, o conhecimento da percepção que os alunos do curso de geografia em Portugal têm em relação a determinados temas da geografia e da educação ambiental.

O objetivo deste artigo foi conhecer a percepção dos alunos portugueses do curso de geografia sobre a educação ambiental, visto que a questão ambiental é um problema que afeta diretamente o destino da humanidade, e, por isso, tem mobilizado governos e sociedade civil.

O compromisso de cada indivíduo no planeta Terra é essencial e insubstituível para a implementação de novas relações com os seus semelhantes e com a natureza, pois a crise ambiental vivida por todos originouse da concepção antropocêntrica, instrumentalizadora e utilitarista da natureza entendida como fonte de recursos (SORRENTINO, 2002).

A Educação Ambiental deve perpassar pela esfera educacional e pelo campo ambiental dialogando com os novos problemas gerados pela crise ecológica e produzindo reflexões, concepções, métodos e experiências que visam construir novas bases de conhecimento e valores ecológicos para esta e para as futuras gerações (CARVALHO, 2004).

É mister que os educadores tenham uma sólida formação científica, pedagógica e humanista, que abarque diferentes questões do mundo atual, como a distribuição mais justa da renda, a conservação dos recursos naturais, a valorização do trabalho humano, as relações comerciais no mundo e a sua interferência na universidade e na vida dos estudantes.

Este artigo segue organizado em cinco partes. A primeira, $O$ papel da universidade na busca por uma sociedade sustentável, traz uma série de reflexões de autores que abordam a formação ambiental cidadã nas 
instituições de ensino, destacando as possibilidades de atuação do ensino superior.

A segunda parte, Procedimentos metodológicos, apresenta as etapas seguidas para a realização desta pesquisa, como a elaboração e aplicação dos questionários submetidos aos alunos do curso de graduação em geografia da Universidade de Coimbra, Portugal.

A terceira parte, Relato de experiência - mobilidade internacional, versa sobre as impressões do autor a respeito de suas vivências (acadêmicas e culturais) ao longo do ano letivo cursado na Universidade de Coimbra. Esta seção apresenta informações de como é estruturado o ensino superior em geografia na Universidade de Coimbra, de modo a possibilitar um detalhamento da formação dos alunos que responderam ao questionário.

A quarta parte, $\mathrm{O}$ que pensam os graduandos em geografia, expõe e discute os resultados obtidos com a aplicação do questionário sobre as condutas e compreensões dos alunos inqueridos acerca de questões ambientais. Neste item, as discussões dos resultados são permeadas por algumas ideias fundamentais de autores que abordam a temática ambiental.

Por fim, as Considerações finais sintetizam as ideias centrais discutidas ao longo deste artigo e ressaltam os aspectos mais relevantes percebidos nas respostas dos alunos.

O estudo apresentado neste artigo procurou conhecer como os alunos de um curso superior em geografia de uma universidade portuguesa concebem a sua relação e a de sua sociedade com o ambiente; temática abordada pelos autores deste artigo no Brasil. Esta análise se faz importante para melhor avaliar a compreensão acerca do ambiente na formação de geógrafos nesta segunda década do século XXI, temática esta tão pertinente à geografia e tão em voga dentro e fora do meio acadêmico na atualidade.

\section{O papel da universidade na busca por uma sociedade sustentável}

A educação deve estar em sintonia com as exigências atuais da sociedade. É preciso criar ambientes educacionais que partam das questões pedagógicas e busquem atender à condição humana, oferecendo elementos para que os indivíduos possam exercer sua cidadania e, assim, participarem com responsabilidade na comunidade local e planetária, priorizando os valores humanísticos, ecológicos e espirituais. Isso requer métodos de ensino, currículos e valores, práticas educacionais diferentes das que estamos habituados a encontrar em nossas instituições de ensino (MORAES, 2007).

Nesse sentido, as instituições de ensino, como espaço coletivo, possuem condições de desenvolver um processo de descoberta mediado pelo diálogo entre professores e alunos, para trazer à tona questões que dinamizam e dão significado às dimensões espaciais e temporais da sociedade. 
Conhecer o contexto social dos estudantes, as características do grupo, são de fundamental importância para o processo de ensino, incluindo as temáticas relacionadas à educação ambiental. A partir delas, o educador trabalhará valores, conceitos, linguagens e atitudes que sejam significativas para a transformação do sujeito autônomo. No contexto da educação, o professor toma o papel de coadjuvante importante no processo ensinoaprendizagem; e o ambiente escolar destaca-se como o espaço onde são estabelecidas diferentes relações, em que os seres humanos, sujeitos sociais e históricos confrontam saberes.

Carvalho (2004) afirma que a formação do indivíduo só faz sentido se pensada em relação com o mundo em que ele vive e pelo qual é responsável sob a perspectiva da tomada de posição de responsabilidade pelo mundo em que vivemos, incluindo aí a responsabilidade com os outros e com o ambiente.

Cabe destacar que a UNESCO, como responsável pela implementação da Agenda 21 Global, no Capítulo 36, "Promoção do ensino, da conscientização e do treinamento", faz referência à década de 2005 a 2014 como a Década da Educação para o Desenvolvimento Sustentável, colaborando, dessa forma, com os desafios e compromissos para a educação superior (PRIETO, 2012).

Esse documento resultante da Conferência da Terra em 1992, ainda em seu Capítulo 36, "Educação, Formação e Consciência Pública", enfatiza que a educação é fundamental para promover o Desenvolvimento Sustentável e melhorar a competência das pessoas para o tratamento de questões relativas ao ambiente e ao desenvolvimento. Nesse sentido, o ensino deve também contribuir para a formação de uma consciência ética e ambiental, bem como de valores, atitudes e comportamentos em consonância com 0 desenvolvimento sustentável, e, dessa maneira, favorecer a participação dos indivíduos em tomadas de decisão coletivas.

Durante a Rio+20, realizada no Rio de Janeiro (14 a 22/06/2012), cerca de 300 faculdades e universidades assinaram a Declaração da Iniciativa de Sustentabilidade da Educação Superior com propósito de reforçar o compromisso de inserção da temática no cerne das atividades das respectivas instituições e dos seus currículos universitários (PRIETO, 2012).

O referido capítulo faz uma referência breve, mas concreta, às Universidades e ao seu papel na construção de um futuro sustentável. Referese também às prioridades atuais do Ensino Superior para o Desenvolvimento Sustentável: desenvolvimento de currículos transdisciplinares em Desenvolvimento Sustentável, investigação científica relacionada com sustentabilidade e formação de uma rede de multiplicadores que promova a consciência ambiental e a sustentabilidade (PRIETO, 2012).

Diante disso, a Educação Ambiental deve ser entendida como produto de diálogo permanente entre concepções sobre o conhecimento, a aprendizagem, o ensino, a sociedade e o ambiente. Desse modo, ela se afirma como promotora de práticas sustentáveis no âmbito universitário e salienta que 
essa questão teria uma efetividade maior se fosse abordada por Programas de Educação Ambiental (PEA). No contexto de uma universidade, os PEA podem contribuir para promover a interação conjunta dos indivíduos em prol da melhoria da qualidade de vida ambiental nas universidades e fora delas.

Atualmente, os desafios com os quais a humanidade se depara são inúmeros, entre eles está a poluição do ar, das águas, dos solos, a extinção de espécies da fauna e da flora. Não se pode deixar de mencionar, também, a exclusão social que assola milhões de pessoas, o desemprego, a desnutrição, a fome, o analfabetismo, pois são problemas de ordem ambiental, melhor enfatizando, problemas socioambientais que emanam de problemáticas decorrentes da interação entre a sociedade e a natureza. Morais (2004, p.12) afirma com propriedade que:

Chegamos a um ponto da jornada humana em que as sociedades vão compreendendo que a alternativa indiscutível está entre renovar-se ou perecer. Nem resta, a tais sociedades, folga de tempo para que tomem as primeiras atitudes, pois problemas mundiais como o aquecimento global, as bruscas mudanças climáticas, o desmedido crescimento demográfico com crise no abastecimento de água potável etc., cobram uma urgência nunca antes conhecida ou enfrentada pela humanidade. [...]

Atualmente exigem-se reflexões acerca da problemática ambiental e também da educação. Novos valores e atitudes devem ser adotados para despertar, em cada indivíduo, o sentimento de pertencimento, participação, solidariedade e responsabilidade na busca de respostas locais e globais para a crise que se enfrenta.

Com a questão ambiental estamos diante de questões de claro sentido ético, filosófico e político. Que destino dar à natureza, à nossa própria natureza de seres humanos? Qual o sentido da vida? Quais os limites da relação da humanidade com o planeta? O que fazer com o nosso antropocentrismo quando olhamos o espaço, o nosso planeta e vemos como ele é pequeno e quando entendemos que somos apenas uma dentre tantas espécies vivas de que nossas vidas dependem? (PORTO-GONÇALVES, 2011, p. 18).

A Educação Ambiental é uma práxis educativa e social que tem por finalidade a construção de valores, conceitos, habilidades e atitudes que possibilitem $o$ entendimento da realidade de vida e a atuação com responsabilidade no ambiente. Nesse sentido, essa contribuição possibilita a implementação de um padrão de civilização e sociedade totalmente distinto do vigente, pautado numa nova ética da relação sociedade-natureza (SORRENTINO, 2002). 
A educação para a sustentabilidade exige modificações nos planos político, social, econômico e cultural. Sustentabilidade para o novo, numa nova relação do ser humano com ele mesmo, entre os seres humanos, entre os países do Norte e os do Sul, entre a sociedade e a Natureza (LEFF, 2001).

Dessa maneira, poder-se-á desenvolver valores ambientais que sejam semelhantes aos da educação e que se estendam aos temas transversais em um sentido integrador de valores como: solidariedade, cooperação, respeito à diversidade, autonomia, participação, responsabilidade e tolerância.

Ao propor qualquer ação educativa, o primeiro passo é conhecer as teorias, conceitos e representações sobre o tema a ser trabalhado e, no caso da Educação Ambiental, é importante compreender como as pessoas pensam e agem no meio ambiente em que vivem. E importante ter conhecimento sobre a percepção que têm do mundo, das coisas e das outras pessoas.

As ações humanas em todos os ambientes e em diferentes situações têm levado o próprio homem a enfrentar difíceis desafios com relação à capacidade finita dos ecossistemas, a manter e a absorver o atual nível de consumo e de crescimento das cidades. Capra (2002) enfatiza que nossas atividades econômicas prejudicam a biosfera e a vida humana de tal modo que, em pouco tempo, os danos poderão tornar-se irreversíveis. Assim, faz-se necessário que essa situação seja reduzida sistematicamente, para que minimizem os impactos causados pelas atividades humanas sobre o meio ambiente natural.

Tristão (2004) enfatiza que a universidade é um dos importantes instrumentos que devem ser utilizados para engendrar novas concepções e novos hábitos na sociedade. Ela se destaca no processo de formação ambiental como um dos atores para a construção coletiva de um futuro sustentável.

Partindo do pressuposto de que a formação de professores se constitui a partir de uma rede de relações, a universidade é um importante contexto a ser explorado porque participa de outros como a política educacional, a pesquisa e a formação continuada dos professores/as em serviço. (TRISTÃO, 2004, p.70)

Ela pode contribuir de maneira efetiva para a construção de uma ciência que encontre alternativas para o desenvolvimento das sociedades de modo sustentável. A prática acadêmica está impregnada de valores, e não pode estar distante das preocupações sociais. Então, a formação ambiental aponta para o redimensionamento das práticas pedagógicas e diretrizes para um saber ambiental articulado com a prática social e com uma estreita relação entre investigação, ensino, difusão e extensão do conhecimento.

O papel da universidade ultrapassa a comunidade acadêmica, pois deve haver uma estreita relação com o mundo exterior, no sentido de buscar definições práticas para os problemas da sociedade, desempenhando, dessa 
maneira, o seu papel social. A sustentabilidade pressupõe investigação científica, aplicação, consistindo em envolvimento de questões políticas e a participação social.

Nesse sentido, a universidade possui o papel importante na formação ambiental e na construção de uma ciência que encontre alternativas para o desenvolvimento das sociedades de modo sustentável. Ela é convidada a dar respostas, propor soluções e formar profissionais comprometidos com o seu espaço de vivência, possui estreita relação com o mundo exterior, no sentido de buscar definições práticas para os problemas da sociedade.

O papel da universidade no processo de formação ambiental aponta para o redimensionamento das práticas pedagógicas e diretrizes para um saber ambiental articulado com a prática social e com estreita relação entre pesquisa, ensino e extensão.

A seguir, serão apresentados os procedimentos metodológicos e os resultados desta pesquisa; tanto os obtidos por meio da aplicação de um questionário, como também os que são fruto deste quase um ano de convivência com alunos e professores de um curso de Geografia que, em alguns pontos, difere em muito dos cursos brasileiros.

\section{Procedimentos metodológicos}

Para a elaboração deste trabalho, foi realizada pesquisa bibliográfica, relato das experiências vivenciadas na mobilidade internacional, aplicação de um questionário e análise dos resultados. Em relação à pesquisa bibliográfica, realizaram-se leituras e análises de textos referentes à temática da educação ambiental, cujas ideias centrais dos autores consultados foram discutidas na seção $O$ papel da universidade na busca por uma sociedade sustentável, e, foram inseridas em meio à discussão dos resultados de modo a dialogar com os mesmos.

O relato de experiências consistiu na exposição das percepções do pesquisador, que, no período em que frequentou o curso de geografia da Universidade de Coimbra, pôde observar as diferenças mais marcantes em relação aos cursos das universidades brasileiras e compreender como ocorre a formação dos geógrafos da referida instituição.

A coleta de dados primários foi realizada através da aplicação de um questionário a cinquenta alunos do curso de geografia da Universidade de Coimbra, distribuídos entre seus três anos de duração. O questionário, elaborado especificamente para este artigo, contempla questões com temáticas que já eram pesquisadas pelos autores deste estudo antes mesmo desse contato com os alunos portugueses.

O questionário foi composto por quinze perguntas, sendo quatro para identificação do perfil dos alunos e 11 sobre a formação e os hábitos dos mesmos em relação à educação ambiental. Destas, cinco questões foram discursivas e seis foram objetivas. 
A aplicação do questionário se deu em sala de aula nos momentos que antecediam as aulas. Para tanto, contou-se com a anuência e contribuição dos professores, que cederam alguns minutos de suas aulas para que os alunos pudessem responder à pesquisa.

$\mathrm{Na}$ sequência, realizou-se a tabulação e análise das respostas do questionário, bem como sua organização para uma melhor compreensão dos resultados, seguida pelas considerações dos autores.

\section{Relato de experiência - mobilidade internacional}

A oportunidade de realizar um intercâmbio de estudos na Universidade de Coimbra foi bastante enriquecedora. A universidade, fundada no ano de 1290, é uma das mais antigas do mundo e a mais tradicional de Portugal, sendo muito conceituada na Europa. É uma das instituições de ensino superior da Europa que mais recebe alunos estrangeiros - o que proporcionou também a convivência com pessoas de origens e culturas muito distintas.

Durante esse período de estudos em Coimbra, foi possível observar que, em vários aspectos, há distinções muito evidentes em relação aos cursos universitários do Brasil. $O$ aluno não é obrigado a assistir às aulas e não há um controle de frequência. Ele pode, se assim preferir, matricular-se nas disciplinas e somente realizar um exame ao final do semestre e, se obtiver no mínimo cinquenta por cento da nota, é aprovado. Porém, via de regra, os estudantes que decidem frequentar as aulas, durante o semestre, têm a oportunidade de realizar outras atividades avaliativas e receber orientações dos professores.

Grande parte dos cursos de graduação, após a adesão ao Processo de Bolonha $^{3}$, passou a ter duração de apenas três anos. Para obter uma melhor formação os alunos cursam, logo em seguida, o mestrado, que tem duração de dois anos. Assim, após cinco anos de estudos os alunos obtêm o título de mestre, o mesmo tempo que, anteriormente ao Processo de Bolonha, levavam para obter apenas o diploma de graduação.

Durante a graduação, o aluno pode optar por cursar Geografia, Geografia e História (com uma formação mais voltada para os temas de geografia) ou História e Geografia (este voltado mais para os temas de história). Esta configuração faz com que, na maioria dos casos, existam alunos de mais de um curso matriculados nas disciplinas, sendo que, algumas disciplinas que são obrigatórias para determinado curso, podem ser oferecidas como optativas aos demais.

Para a aplicação dos questionários, optou-se por abordar os alunos das três modalidades de curso citadas acima. Em primeiro lugar, porque devido ao

\footnotetext{
3 O Processo de Bolonha, firmado pelos ministérios da educação de nações europeias no ano de 1999 , tem como intuito padronizar os cursos superiores na Europa para, assim, facilitar o reconhecimento dos diplomas nos países que aderiram ao tratado, além de favorecer uma maior circulação de pesquisadores entre as instituições de ensino superior no continente.
} 
fato de as turmas abrangerem alunos dos três cursos, seria demasiado difícil acessar apenas os que cursam Geografia. E em segundo lugar, mesmo os cursos em que o enfoque não é apenas geografia, os alunos, ao longo da graduação, recebem formação em geografia. Desse modo, foi possível verificar como é concebida a questão da educação ambiental pelos alunos da Universidade de Coimbra que recebem formação em geografia. A seguir, são apresentadas e analisadas essas informações.

\section{O que pensam os graduandos em geografia}

Por meio da aplicação do instrumento de pesquisa, o questionário, foi gerada uma série de dados referentes aos alunos que frequentavam as disciplinas do curso de geografia da Universidade de Coimbra. Com base nos dados obtidos, apresentam-se abaixo algumas características dos alunos que responderam ao questionário.

Observa-se que a maioria das pessoas que responderam à pesquisa são do sexo feminino, representando um total de $58 \% ; 42 \%$ são as pessoas do sexo masculino. Em relação à idade dos alunos, 20\% possuem entre 18 e 20 anos, $22 \%$ possuem entre 21 e 25 anos, $4 \%$ possuem entre 26 e 30 anos, $2 \%$ possuem entre 31 e 40 anos e outros $2 \%$ possuem entre 41 e 50 anos. Em relação ao curso de graduação em que estão matriculados, $70 \%$, é do curso de Geografia, seguido por $16 \%$ do curso de História e Geografia e por $14 \%$ do curso de Geografia e História. No que se refere ao estágio de andamento da graduação, a maior parcela dentre os alunos pesquisados estão no $2^{\circ}$ ano de curso, $46 \% ; 36 \%$ estão no $1^{\circ}$ ano e $18 \%$ estão no $3^{\circ}$ ano.

As quatro questões seguintes diziam respeito à percepção dos alunos em relação aos conhecimentos sobre educação ambiental. Primeiramente, foi perguntado se consideravam que a instituição em que estudavam realiza uma abordagem efetiva sobre a questão ambiental. Na sequência, questinou-se se a instituição estaria em sintonia com as necessidades atuais referentes aos problemas ambientais (Figura 1).

revista brasileira
A instituição está em sintonia com as necessidades referentes aos problemas ambientais?

A instituição realiza abordagem efetiva sobre a questão ambinetal?

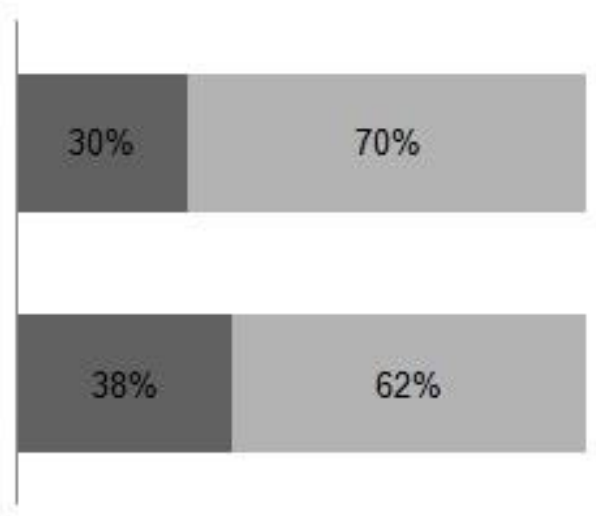

- Sim Não

Figura 1: Impressão dos alunos em relação à abordagem e à sintonia da universidade com a questão ambiental. Fonte: Pesquisa direta, 2011. 
As respostas a essas duas perguntas evidenciam uma crítica dos alunos à abordagem que a universidade propicia às questões ambientais. Mais da metade dos alunos consideraram, desta forma, que a universidade deveria ser mais atuante nas discussões frente aos problemas ambientais contemporâneos.

A Educação Ambiental deve ser entendida como educação política, uma vez que reivindica e prepara os cidadãos e as cidadãs para exigir e construir uma sociedade com justiça social, cidadania (nacional e planetária), autogestão e ética nas relações sociais e com a natureza (REIGOTA, 2012).

Especificamente sobre a abordagem dos cursos, os alunos foram indagados se, durante a graduação, foram trabalhados conhecimentos sobre educação ambiental e sustentabilidade: $44 \%$ dos respondentes afirmaram ter adquirido esse conhecimento integrado aos conteúdos dos módulos ou disciplinas, 32\% responderam ter adquirido de forma esporádica e superficial, $6 \%$ responderam ter adquirido em um módulo específico sobre o assunto e $18 \%$ disseram não ter recebido nenhuma informação a respeito.

As instituições de ensino superior formam indivíduos para atuar na sociedade, por isso têm um papel fundamental na disseminação da educação ambiental, na produção de conhecimentos e ações sustentáveis. Além disso, seu papel é fundamental como referência nessas práticas.

De acordo com Tauchen e Brandli (2006), duas correntes abordam o papel das instituições de ensino superior no que se refere ao desenvolvimento sustentável: uma relacionada à preocupação com a inserção da Educação Ambiental nos currículos e à formação acadêmica dos futuros profissionais responsáveis por decisões na sociedade; e outra que destaca a postura de algumas instituições de ensino superior na implementação de sistemas de gestão ambiental em seus campi universitários.

Indagados sobre como consideram o conhecimento obtido no decorrer do curso acerca da Educação Ambiental, $52 \%$ dos alunos disseram ter recebido conhecimentos suficientes para não cometer infrações, 22\% avaliaram os conhecimentos recebidos como pouco ou ruins, $10 \%$ cosideraram os conhecimentos adquiridos como muito bons, e, $10 \%$ disseram não possuir nenhum cohecimento em relação à Educação Ambiental, que tenha sido adquirido no decorrer do curso.

A reflexão sobre as práticas sociais, em um contexto marcado pela degradação permanente do meio ambiente e do seu ecossistema, cria uma necessária articulação com a produção de sentidos sobre a Educação Ambiental. O desafio é formular uma Educação Ambiental que seja crítica e inovadora em dois níveis: formal e não formal. Assim, ela deve ser acima de tudo um ato político voltado para a transformação social.

Perguntou-se aos estudantes como adquiriram os conhecimentos sobre o meio ambiente. Como era possível apontar mais de uma alternativa como resposta, 96\% responderam ter adquirido esses conhecimentos por meio da mídia (TV, rádio, internet), 32\% por meio de folders ou manuais de órgãos 
ambientais, $12 \%$ por meio de cursos ou palestras promovidas pela Universidade, e, 10\% pela atuação de ONGs.

Maturana e Varela (2001) afirmam que o fenômeno de conhecer está diretamente ligado à experiência, e este processo, pelo qual o indivíduo constrói o seu conhecimento, é pessoal, individual e subjetivo. O conhecimento não é somente absorvido da forma em que se apresenta no mundo. A ação ou a experiência ocorrem de maneira circular, dentro da estrutura humana, e o ato de conhecer é que faz surgir um mundo.

Assim, no contexto atual, a Educação Ambiental emerge como responsabilidade social dos órgãos públicos, das empresas e escolas como um campo de estudos, vivência e ações voltadas para a criação de condições indispensáveis para que os homens e as comunidades sejam estimulados a contribuir para melhoria de suas condições de vida.

A Educação Ambiental deve enfatizar o estudo do meio ambiente onde vivem os alunos/as procurando levantar os principais problemas cotidianos, as contribuições da ciência, das artes, dos saberes populares, ou seja, os conhecimentos necessários e as possibilidades concretas para a solução deles. Reigota (2012) enfatiza que é primordial possibilitar a participação e convidar à participação. Dessa maneira 0 aluno constrói e desenvolve progressivamente o seu conhecimento e seu comportamento juntamente com colegas, professores e familiares. Esse processo pressupõe o diálogo entre todos os envolvidos.

Finalizando as questões objetivas, indagou-se aos estudantes como eles percebem a questão ambiental no planejamento de seus municípios. Para 34\% dos alunos pesquisados, embora seja importante, a questão ambiental ainda é muito ignorada. Para $32 \%$, a importância está na sintonia que o produtor rural deve ter com os conhecimentos sobre os problemas ambientais e a produção sustentável. Para $10 \%$, as informações sobre o assunto são muito superficiais e não provocam alterações significativas na prática. Para $2 \%$, o meio ambiente é prejudicado pela utilização de insumos químicos, necessários para garantir uma maior produtividade. Completando, $18 \%$ dos inqueridos desconhecem a questão ambiental no planejamento do município e $4 \%$ não têm opinião a respeito.

Segundo Tuan (1980), na percepção ambiental da paisagem estão intrínsecos os laços entre o meio ambiente e a visão de mundo do homem. A percepção ambiental é individual e, no processo de interação, há uma variedade de elementos que a integram. $O$ autor define a percepção como a resposta dos sentidos aos estímulos externos e como atividade proposital, na qual certos fenômenos são claramente registrados, enquanto outros retrocedem ou são bloqueados. $O$ que percebemos tem valor para nós, para a sobrevivência biológica e para propiciar algumas satisfações que estão enraizadas na cultura.

Nesse, sentido, os diferentes problemas vivenciados atualmente exigem um (re)pensar e (re)fazer com relação às bases de sustentação do Planeta. Dramatizar a situação não é o que se pretende, mas sim refletir sobre o momento vivido. Não resta alternativa que não seja reconhecer a existência 
dos limites biológicos e físicos da natureza, sendo esta a parte principal da sustentabilidade para se estabelecerem rumos em busca da redução dos impactos ambientais negativos. Esses são causados pela busca de crescimento econômico e produção de bens. O sistema econômico colocou no centro da vida social necessidades que só ele pode satisfazer, somente ele possibilita a satisfação dessas necessidades a uma parcela da população.

Sachs (1986) já destacava que urge avançar nas discussões e ações ao invés de questionar o crescimento como ora se apresenta. É mais interessante utilizar padrões alternativos de crescimento, baseados em uma função-objetivo diferentes, organizados e instrumentalizados de maneira a minimizar os impactos ecológicos negativos e o uso de recursos exauríveis. Surge, então, o grande desafio que é a redefinição das formas e usos do crescimento e não a desistência do crescimento. É preciso projetar novos estilos de desenvolvimento com objetivo de harmonizar o crescimento econômico e social com uma gestão racional do ambiente enfatizando a dimensão ambiental, o conceito de desenvolvimento e de planejamento do desenvolvimento.

A última parte do questionário compreendeu cinco questões discursivas. Na primeira delas, foi pedido que os alunos apresentassem sugestões para que a Universidade adotasse práticas que considerassem a sustentabilidade e a Educação Ambiental (figura 2). A realização de palestras e conferências sobre a temática foi sugerida por $44 \%$ dos alunos pesquisados. Também se destacaram sugestões para diminuir o consumo de água e energia (22\%), como a utilização de luzes econômicas e com sensores de presença, instalação de painéis solares nos prédios da Universidade e torneiras de fechamento automático. Para $20 \%$ dos alunos, seria importante a instalação de "ecopontos", com cestos que separam os resíduos por tipo de material, para reciclagem. Outros $20 \%$ dos alunos citaram a realização de campanhas de envolvimento e sensibilização com concursos culturais, trabalhos de campo e comemoração de datas de conscientização, como o dia do meio ambiente, dia da água, etc. Completando, $12 \%$ sugeriram a criação de uma disciplina específica em Educação Ambiental a ser oferecida durante a graduação e 10\% sugeriram melhorar a informação dos alunos por meio de cartazes e panfletos. $14 \%$ dos alunos ainda ofereceram outras sugestões, como a instalação de bicicletários (para incentivar a diminuição do uso de automóveis), utilização de mídias digitais em vez de mídias impressas e lançar mão de copos reutilizáveis nos refeitórios, ao invés de copos descartáveis. 


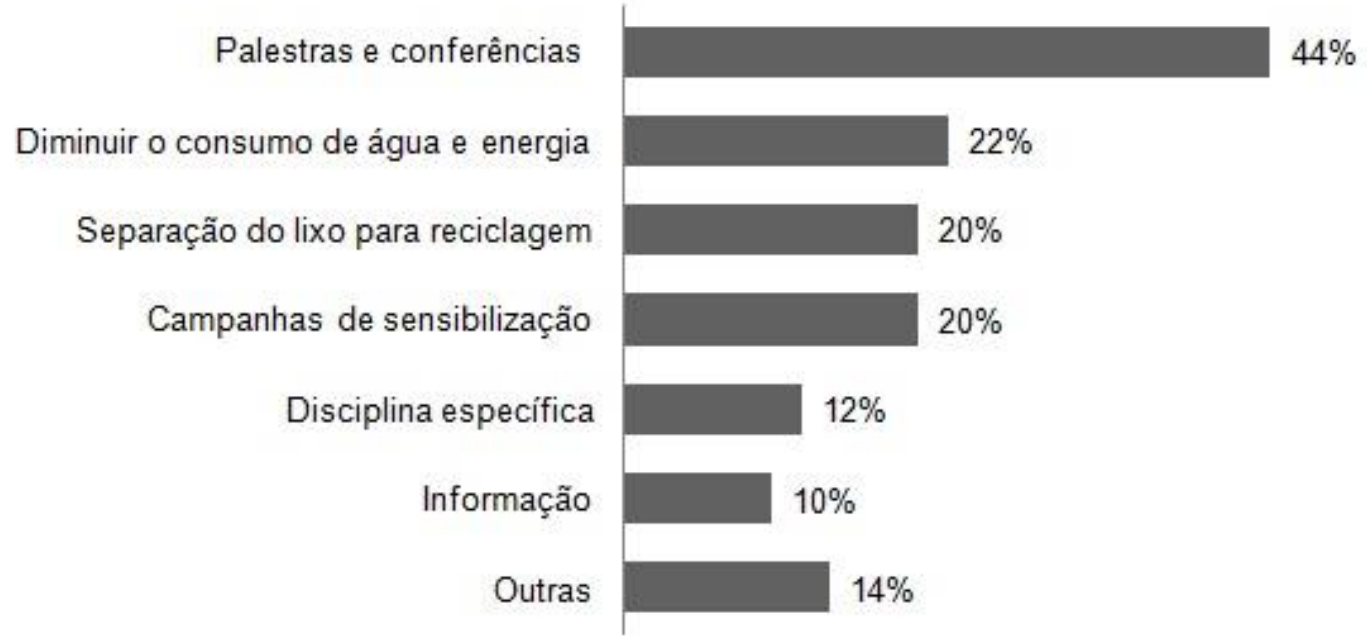

Figura 2: Sugestões para que a Universidade adote práticas que considerem a sustentabilidade e a Educação Ambiental. Fonte: Pesquisa direta, 2011.

$\mathrm{Na}$ sequência, foi perguntado aos alunos como eles poderiam contribuir para melhorar o seu espaço de vivência. $40 \%$ responderam que poderiam adotar práticas ecologicamente corretas, como respeitar o meio ambiente, colocar em prática os conhecimentos adquiridos, alertar as outras pessoas sobre a importância de se preservar o meio ambiente, etc. $24 \%$ apontaram que poderiam separar o lixo para reciclagem, $16 \%$ disseram que poderiam utilizar mais os transportes públicos, $14 \%$ responderam que poderiam jogar o lixo nos cestos, $12 \%$ disseram que poderiam economizar água e $24 \%$ apontaram outras ações, como economizar energia, criar e ajudar a manter espaços verdes, racionalizar o consumo e a utilização de recursos e participar de grupos de trabalho que atuam em prol do meio ambiente. $8 \%$ dos alunos pesquisados não responderam.

Sabe-se que a educação para a formação de valores sustentáveis ocorre para além da escola. Mas, é necessário construir um paradigma curricular para recuperar o modo humano autêntico de relação com o mundo natural para enfrentar de modo direto os desafios ecológicos com os quais nos deparamos (GADOTTI, 2009).

Quando indagados sobre o que os alunos entendem por Educação Ambiental, várias foram as respostas. Sendo assim, os apontamentos foram agrupados de acordo com a semelhança de seus temas. Para $32 \%$ dos alunos pesquisados, Educação Ambiental envolve os conhecimentos que se adquirem e possibilitam utilizar de forma racional os recursos do meio ambiente. Para $18 \%$, Educação Ambiental engloba o uso sustentável dos recursos, sem comprometer sua disponibilidade para as gerações futuras. Em 16\% das respostas, Educação Ambiental significa proteger e conservar o meio ambiente. Para $10 \%$ dos estudantes, se traduz em ações que conservam e, ao mesmo tempo, prejudicam o menos possível o ambiente. $8 \%$ dos alunos consideram que a Educação Ambiental consiste em reconhecer os problemas ambientais e 
saber como evitá-los e/ou corrigi-los. $14 \%$ dos inqueridos apresentaram outras considerações e $2 \%$ não responderam.

Como aduz Loureiro (2004, p. 71):

Em termos de apresentação dos procedimentos metodológicos que permitem trabalhar com tal método, considerando, para isso, o fato dos documentos nacionais e internacionais sobre Educação Ambiental destacarem a participação como um dos seus pressupostos indissociáveis, sou por afirmar que as metodologias participativas são as mais propícias ao fazer educativo ambiental. Participar trata-se de um processo que gera a interação entre diferentes atores sociais na definição do espaço comum e do destino coletivo. Em tais interações, ocorrem relações de poder que incidem e se manifestam em níveis distintos em função dos interesses, valores e percepções dos envolvidos. Participar, aqui, é promover a cidadania, entendida como realização do "sujeito histórico" oprimido. Num certo sentido rousseauniano, a participação é o cerne do processo educativo, pois desenvolve a capacidade do indivíduo ser "senhor de si mesmo", sendo, para isto, preciso libertar-se de certos condicionamentos políticos e econômicos também.

Para conhecer quais são as ações cotidianas dos alunos que contribuem para evitar a degradação ambiental, foi perguntado aos estudantes o que eles fazem de concreto que demonstra uma preocupação com o meio ambiente. $O$ maior destaque foi para a separação do lixo para reciclagem; a prática foi citada por $78 \%$ dos alunos pesquisados. Também se destacaram a economia de água com $26 \%$, a utilização de transportes públicos com $22 \%$, a economia de energia com $20 \%$, jogar o lixo nos locais destinados para este fim com $20 \%$, e, não degradar os espaços verdes com $8 \%$. 16\% dos alunos ainda citaram outras práticas, e $4 \%$ não citaram prática alguma, conforme o gráfico abaixo (figura 3).

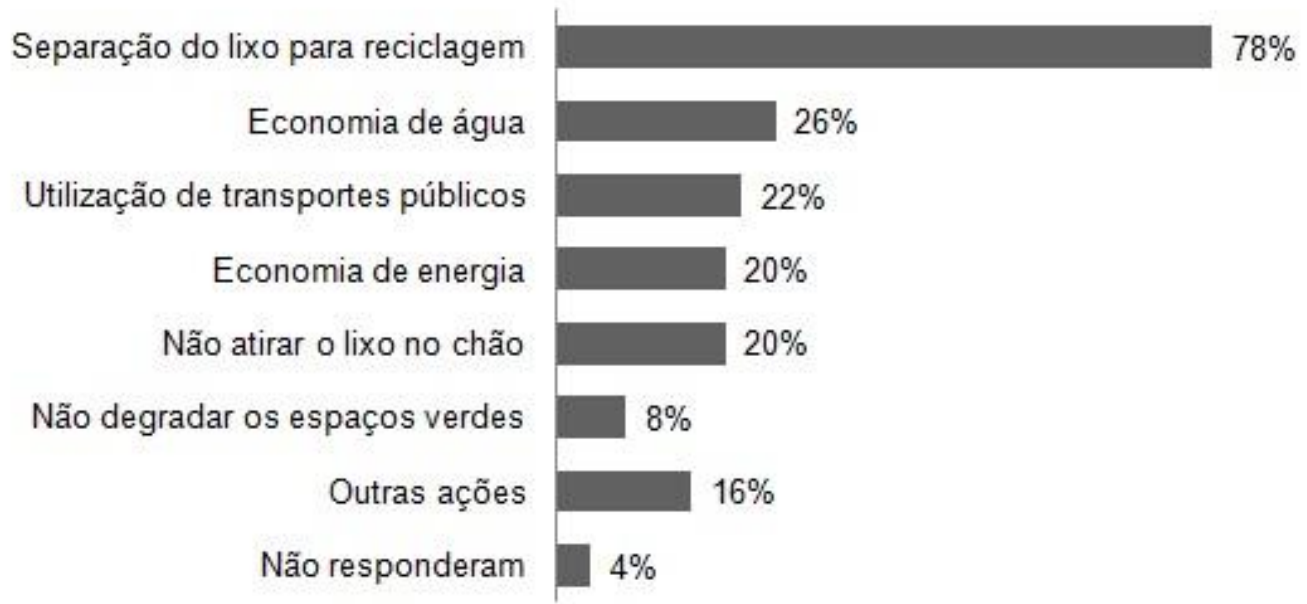

Figura 3: Ações concretas que demonstram preocupação com o Meio Ambiente.

Fonte: Pesquisa direta, 2011. 
De acordo com Carvalho (2004), o sujeito ecológico é o modo ideal de ser e viver orientado pelos princípios do ideário ecológico. Deve buscar experimentar, no cotidiano, atitudes ecologicamente orientadas. Somos convidados a estabelecer novo pacto - contrato natural - construir cultura ecológica que compreenda natureza e sociedade como dimensões interrelacionadas. Neste contexto, a formação do indivíduo só faz sentido se pensada em relação com o mundo em que ele vive e pelo qual é responsável.

$\mathrm{Na}$ última pergunta do questionário, solicitou-se que os alunos definissem o que é meio ambiente e qual a importância dele em suas vidas. Muitas respostas foram semelhantes, podendo ser agrupadas em três categorias de significado. Para $46 \%$ deles, o meio ambiente é todo o espaço que rodeia o homem, todo o espaço no qual o homem está inserido, constituído por fatores naturais e resultante de ações antrópicas. Para $28 \%$, o meio ambiente é considerado em uma perspectiva mais naturalista, sendo definido como os espaços verdes, caracterizados por uma maior presença da fauna e da flora. Para $24 \%$, o meio ambiente constitui os espaços onde ocorrem as interações que possibilitam a vida na Terra, ou seja, base de sustento do homem no que diz respeito às suas necessidades básicas (como obtenção de alimento, oxigênio, água) e à manutenção da vida em sociedade (trabalho, cultura, economia, produção). Quanto ao significado do meio ambiente para a vida, em todas as respostas, ficou evidente que ele é primordial para todos os seres vivos do planeta.

Embora a expressão 'meio ambiente' seja amplamente confundida com natureza, mesmo nos meios acadêmicos, a questão ambiental diz respeito ao modo como a sociedade se relaciona com a natureza - qualquer sociedade e qualquer natureza - e isso inclui também as relações dos seres humanos entre si e destes com a natureza, "proteger (ou sanear) o meio ambiente", por exemplo soa estranho uma vez que o que deve ser protegido (ou saneado) são os recursos naturais, ou um dado ecossistema, e não todas ou quaisquer relações com a natureza (BRUGER, 2004, p. 56).

Carvalho (2004) afirma que a Educação Ambiental é parte do movimento ecológico. Surge da preocupação da sociedade com o futuro da vida no planeta e com a qualidade da existência das gerações presentes e das gerações futuras. A Educação Ambiental é herdeira direta do debate ecológico e está entre as alternativas que visam construir novas maneiras de os grupos sociais se relacionarem com o meio ambiente.

A Educação Ambiental foi primeiramente concebida pelos movimentos ecológicos como uma prática de conscientização para chamar atenção para a finitude e má distribuição dos recursos naturais e para envolver os cidadãos em ações sociais ambientalmente apropriadas. Posteriormente, a Educação Ambiental foi se transformando em uma proposta educativa, ou seja, dialoga 
com o campo educacional, com suas tradições, teorias e saberes (CARVALHO, 2004).

A mudança de percepção do aluno dá-se na problematização de uma realidade concreta, no entrechoque de suas contradições. Isso implica um novo enfrentamento do homem com sua realidade. Implica "ad-mirá-la" em sua totalidade: vêla de "dentro" e, desse "interior", separá-la em suas partes e voltar a admirá-la, ganhando assim uma visão mais crítica e profunda da sua realidade que não condiciona. Implica uma "apropriação" do contexto; uma inserção nele; um não ficar "aderido" a ele; um não estar quase "sob" o tempo. Implica reconhecer-se homem. Homem que deve atuar, pensar, crescer e transformar e não adaptar-se fatalisticamente a uma realidade desumanizante. (FREIRE, 2002, p. 38).

A educação é um ato político. Acontece quando estabelece meios de superação da dominação e exclusão (FREIRE, 2002). A educação compatível com a Educação Ambiental ocorre com uma ação simultaneamente reflexiva e dialógica, mediada pelo mundo de modo a contribuir para a tomada de consciência de educadores e educandos na transformação das condições de vida.

\section{Considerações finais}

Com base nas análises apresentadas, verifica-se que existe um certo conhecimento por parte dos estudantes do curso de Geografia da Universidade de Coimbra a respeito da Educação Ambiental. Percebe-se que os conhecimentos adquiridos pelos estudantes durante a graduação contribuem para a sua formação, mas a ausência de uma disciplina voltada especificamente para a Educação Ambiental é sentida pelos alunos, tanto que, para mais de $60 \%$ deles, a abordagem que recebem, ao longo da graduação, é insuficiente para formar-lhes como sujeitos ecológicos, com conhecimentos plenos referentes ao meio ambiente e o mais importante, capazes de, com consciência, realizar as ações que causem o mínimo de danos ambientais.

É interessante constatar as ações efetivas, praticadas pelos estudantes, que colaboram para evitar impactos negativos sobre o meio ambiente. Estando inseridos em uma sociedade mais desenvolvida do que a brasileira em relação à consciência e aos cuidados com o meio ambiente, ampla maioria dos estudantes portugueses que responderam ao questionário disseram separar o lixo para reciclagem. Isto se deve por haver, naquele país, um programa de coleta seletiva consolidado e eficiente, que abrange amplamente a população.

Cabe ressaltar também a consciência sobre o uso do transporte público, que traz benefícios maiores à coletividade, tanto no que diz respeito à qualidade do ar quanto na fluidez do trânsito; ao passo que, no Brasil, ainda impera uma preferência individualista pelo transporte particular que, associado 
à ineficácia dos sistemas públicos de transportes, piora a qualidade atmosférica e torna o trânsito caótico, sobretudo nos grandes centros urbanos.

$\mathrm{Na}$ atualidade, como comprovado com esta pesquisa, deve-se destacar a importância da mídia em relação à tomada de consciência das pessoas sobre as questões ambientais. Jornais televisivos e impressos, programas de TV, filmes e, mais recentemente, as redes sociais da Internet têm contribuido para atingir um número cada vez maior de pessoas, expondo a importância de se utilizar de modo consciente os recursos naturais.

Observou-se, neste estudo, que as abordagens em relação a práticas ambientais saudáveis podem e devem se fazer mais presentes em todas as áreas do conhecimento. Para isto, é de suma importância que se pesquisem e se divulguem as concepções que os estudantes têm sobre o meio ambiente. Este debate é primordial para se pensar nas estratégias mais eficientes para a formação de indivíduos comprometidos com a qualidade ambiental.

Assim, as instituições de ensino, os conteúdos e os papéis dos educadores e dos educandos são colocados em uma nova situação, não apenas relacionada com o conhecimento, mas sim com o uso que fazemos dele e de sua importância para a nossa participação cidadã cotidiana.

\section{Agradecimentos}

Agradecemos aos professores e alunos da Universidade de Coimbra que, gentilmente, cederam alguns minutos de suas aulas para a aplicação dos questionários, primordial para a realização desta pesquisa.

\section{Referências}

BRUGER, P. Racionalidade ambiental e conceito de meio ambiente. In: BRUGER, P. Educação ou Adestramento ambiental. 3.ed. Chapecó:Argos, 2004. p. 54-66.

CAPRA, F. As conexões ocultas. Tradução de Marcelo Brandão Cipolla. São Paulo: Cultrix, 2002.

CARVALHO, I.C. Educação ambiental: a formação do sujeito ecológico. São Paulo: Cortez, 2004.

FREIRE, P. Pedagogia da autonomia. São Paulo: Paz e Terra, 2002.

GADOTTI, M. Pedagogia da Terra. 6.ed. São Paulo: Peirópolis, 2009.

LEFF, E. Saber ambiental. Tradução de Lúcia Mathilde Endlich Orth. Petrópolis: Vozes, 2001.

LOUREIRO, C.F.B. Educação Ambiental Transformadora. In: LAYRARGUES, P.P. (Org.). Identidades da educação ambiental brasileira. Brasília: MMA, 2004. p. 65-84. 
MATURANA, H.R.; VARELA, F. J. A árvore do conhecimento: as bases biológicas da compreensão humana. São Paulo: Palas Athena, 2001.

MORAES, M.C. O paradigma educacional emergente. $13^{a}$ ed. São Paulo: Papirus; 2007. p.112.

MORAIS, R. Educação, mídia e meio-ambiente. Campinas: Alínea, 2004. Coleção Educação em debate.

PORTO-GONÇALVES, C.W. O desafio ambiental. 2. ed. Rio de Janeiro: Record, 2011.

PRIETO, E.C. Universidade Sustentável: desafios e compromissos para implantação da Educação e Gestão Ambiental na Universidade Federal de Uberlândia- MG. 2012. 148 f. Tese (Doutorado em Geografia) - Instituto de Geografia, Universidade Federal de Uberlândia, Uberlândia, 2012.

REIGOTA, M. O que é Educação Ambiental. 2.ed.São Paulo: Brasiliense, 2012.

SACHS, I. Ecodesenvolvimento: Crescer sem destruir. Tradução de Eneida Araújo. São Paulo: Vértice, 1986.

SORRENTINO, M. Desenvolvimento sustentável e participação: algumas reflexões em voz alta. In: LOUREIRO, C.F.B., LAYRARGUES, P.P.; CASTRO, S.C. (org) Educação ambiental: repensando o espaço da cidadania. 2. ed. São Paulo: Cortez, 2002. p.15-22.

TAUCHEN, J.; BRANDLI, L.L. A gestão ambiental em instituições de ensino superior: modelo para implantação em campus universitário. Revista Gestão e Produção [online], São Carlos, vol.13, n.3, p. 503-515, 2006.

TRISTÃO, M. A educação ambiental na formação de professores: redes de saberes. São Paulo: Annablume, 2004

TUAN, Yi-fu. Topofilia: um estudo da percepção, atitudes e valores do meio ambiente. São Paulo: Difel, 1980. 